\title{
Reproducibility of task description questionnaire among brazilian pregnant workers
}

\author{
Priscila Cibils da Rosa', Géssica Maria Moreira', Luís Mochizuki², Fabiana Flores Sperandio
}

\begin{abstract}
Background: The increase in the number of pregnant women working to the end of gestation has attracted interest in studying the effects of work on maternal fetal health. A task description questionnaire (TDQ) was developed to evaluate pregnant women and labor tasks performed in this period. Objectives: The purpose of the study was to evaluate the reproducibility of the TDQ and its questions regarding the labor tasks performed by pregnant workers. Methods: Test-retest reproducibility was performed with data collected at seven-day intervals in 37 pregnant women. A Spearman test and $\mathrm{k}$ coefficients were calculated for test-retest agreement. Results: With regard to $\mathrm{k}$, the results showed good to total agreement for questions 3 and 4 . The Spearman correlation was excellent to moderate (for questions 5 and 6 ). Conclusions: The results of the reproducibility of the TDQ reflected the good understanding of this tool, because it was simple, easy and fast to apply. A TDQ can detect the need for changes in the occupational environment of pregnant workers. This ensures the examination of maternal fetal health and safety.
\end{abstract}

Keywords: Pregnancy, Work, Reproducibility of Findings, Ergonomics, Task Description Questionnaire.

\section{INTRODUCTION}

Over the last few decades, women's participation in labor force activities has expanded and become important in terms of sociocultural and economic changes ${ }^{(1-3)}$. In many countries, half of the labor force is made up of women, who are usually in their reproductive period, and when pregnant, they keep working until the end of the gestation and the majority are employed full-time ${ }^{(4-6)}$. The effects of working during pregnancy on maternal fetal health are not clear; however, studies suggest that the maternal job strain may cause preterm delivery and affect children's neurodevelopment ${ }^{(5-9)}$. Pregnant women are more sensitive to ergonomic and environmental challenges, and this becomes particularly true in the later stages of pregnancy. Identifying such ergonomic limits in pregnancy leads to an improved understanding of the professional demands and working conditions that interfere with the health, safety and productivity of the pregnant worker ${ }^{(10,11)}$. To understand labor tasks, conditions and activities it is necessary to understand how workers feel ${ }^{(12,13)}$. Questionnaires are available to evaluate interventions and decisions during the care process and health promotion; to investigate environmental conditions and the self-perception of workers, it is preferable to analyze professional tasks ${ }^{(14)}$, as well as to understand the relation between labor activity and pregnancy ${ }^{(15)}$.

The Task Description Questionnaire (TDQ) assesses problems that pregnant women experience in the workplace and identifies risk factors for maternal fetal health ${ }^{(16)}$. Currently the questionnaire only exists in English language. Given the rising rates of pregnant women in the global workforce, the questionnaire needs to be translated into other languages. In the current project, the task description questionnaire was translated into Portuguese ${ }^{(15)}$. Because this is the first time the questionnaire has been translated into Portuguese, the reliability and reproducibility of this version have not been measured. The comparison of repeated measures ${ }^{(17)}$ and the TDQ has reproducible results ${ }^{(16,18)}$, which are unknown. Thus, two important methodological questions emerge: What is the reproducibility of the TDQ? Is it similar to the original version of this questionnaire? The aim of this study was to evaluate the reproducibility of the TDQ and the questions related to the professional tasks performed by pregnant workers.

\section{METHODS}

\section{Design and participants}

The study was approved by the Committee of Ethics in Research on Human Beings of the State University of Santa Catarina (number 1.483.820). To calculate the sample size, a post hoc analysis, using G*Power Data Analysis software version 3.1.9.2, was applied. Considering a Pearson correlation 
of 0.40 , a significance level of 0.05 and power of 0.80 , at least 34 women were eligible to join our study. Pregnant women were invited to attend prenatal care classes at healthcare community centers and at a University Physical Therapy Center in Florianópolis, Santa Catarina State, Brazil. The inclusion criteria were pregnant women in the second or third gestational trimester; similar professions to the original article; working in a registered job (having legal documents for the employment register); and being able to understand the Portuguese language. The exclusion criteria were being on maternity leave; not giving a second interview; missing any evaluation; being fired; having twins; being diagnosed or self-reported as having psychiatric or psychological illnesses and high-risk gestation, such as hypertension and gestational preeclampsia.

\section{Task description questionnaire}

The TDQ was created and validated by Cheng et al. ${ }^{(16)}$, and translated and adapted into the Brazilian culture by Sperandio et al. ${ }^{(15)}$ to evaluate employed pregnant women in a paid job, to track their labor conditions and the physical and psychological changes at labor facilities. This questionnaire can be self-applied or applied in an interview, in as little as 10 minutes. Six questions $\left(Q_{n}, n=\right.$ question number $)$ ask about labor activity and facilities available $\left(Q_{1}\right.$ and $\left.Q_{2}\right)$; to identify stressor mechanisms $Q_{3}$ presents 22 subitems on a nominal scale (yes/no) to identify weightlifting with the hands (lifting, loading, pulling and pushing); posture (handling of objects, movements with the trunk); posture at work (sitting or standing); pace of work; and others (environment and stress) present in their task; to identify barriers to performing labor tasks $\left(Q_{4}\right.$, yes/no for eight factors and rank them in order of difficulty); and to grade (Likert scale of 10 points from zero intensity to 10 /maximum intensity) the effort $\left(Q_{5}\right)$ and discomfort $\left(Q_{6}\right)$ felt in performing the tasks.

\section{Reproducibility}

The test and retest reproducibility of the TDQ was measured by comparing the total scores from seven days of measures ${ }^{(18,19)}$, using the same time interval as the original study $^{(16)}$. To ensure that the data would be collected correctly, the researchers underwent prior training on the TDQ instrument, mainly in relation to understanding the items of the instrument.

\section{Statistical analysis}

Answers to all questions in the TDQ are depicted as mean, standard deviation and frequency. The level of significance was $p<0.05$. This information was used to fill in spreadsheets (Excel, Windows Office, 20.0, Portuguese version) and statistics were run in SPSS version 20. Reliability ( $\mathrm{K}$ index) was calculated for $Q_{3}$ and $Q_{4}$ gestational trimester data. This index measures the degree of agreement (reliability/precision), in addition to what would be expected by chance. Spearman correlation $^{(1,16)}$ was also used to calculate the reliability level of the TDQ. Landis and Koch ${ }^{(20,21)}$ classified $\mathrm{k}$ in bands: $\mathrm{k}>0.75$ is excellent agreement, $0.40<\mathrm{K}<0.75$ is good agreement and $\mathrm{K}<0.40$ is poor agreement ${ }^{(16)}$. The maximum agreement is $\mathrm{K}=1$.0. For $\mathrm{Q}_{4}$ and $\mathrm{Q}_{6}$, descriptive statistics were used, and in $Q_{5}$ and $Q_{6}$, Spearman correlation $\rho$ was applied. The correlation coefficient was interpreted as follows: $0.7<\rho<1.0$ is good to excellent correlation; $0.5<\rho<0.75$ is moderate to good correlation; $0.25<\rho<0.5$ is weak correlation; and $0.0<\rho<0.25$ is no correlation ${ }^{(22)}$.

\section{RESULTS}

The reproducibility of the TDQ was tested among 37 pregnant women, 18 in the second trimester and 19 in the third trimester. Their professional activities were: education (1), health service (8), administration (13), general services/sales (13) and others (2). Their mean age was 34 years (ranging from 19 to 41 years old). The average time taken to apply the TDQ in the interviews was 9 minutes (ranging from 7 to 12 minutes). The smallest calculated $\mathrm{k}$ index was 0.51 for all comparisons we performed within the TDQ; therefore, according to Sim and Wright $(2005)^{(23)}$, this $\mathrm{K}$ index indicates that our sample size has at least $80 \%$ power. For test-retest agreement in $\mathrm{Q}_{3}$, the $\mathrm{k}$ index was calculated (Table 1 ) separately for the second and third gestational trimesters. For the second-trimester $\mathrm{Q}_{3}$ data, $40.9 \%$ of 22 items had maximum reliability ( $k=1), 50 \%$ had excellent reliability $(0.76<\kappa<0.88)$ and $9.1 \%$ had good reliability $(0.67<k<0.72)$. For the third trimester, $13.6 \%$ of the items had maximum reliability $(\mathrm{k}=1), 54.5 \%$ had excellent reliability $(0.75<\mathrm{k}<0.89)$ and $31.8 \%$ had good reliability $(0.51<\mathrm{k}<0.73)$.

For $\mathrm{Q}_{3}$, the Spearman correlation $\rho$ was calculated to measure the reliability of the 22 questions in the second and third gestational trimesters. For the second trimester, $21(95.4 \%)$ had an excellent correlation, $(0.75<\rho<1.0)$ and only one item had a moderate correlation $(\rho=0.67)$. For the third trimester, 16 items (72.7\%) had an excellent correlation $(0.75<\rho<1.0)$ and six items $(27.2 \%)$ had a moderate correlation $(0.53<\rho<0.72)$. For $Q_{4}$, the $k$ coefficients were calculated between test and retest for the items that make the task difficult in the second and third gestational trimesters (Table 2). For the second trimester and eight $\mathrm{Q}_{4}$ items, four had maximum reliability $(\mathrm{k}=1)$, two had excellent reliability $(0.77<\mathrm{k}<0.88)$ and two had good reliability $(0.60<\mathrm{k}<0.65)$. For the third trimester, three items had maximum reliability $(\mathrm{K}=1)$, three had excellent reliability $(0.87<\mathrm{K}<0.88)$ and two had good reliability $(0.61<\mathrm{k}<0.73)$.

For $\mathrm{Q}_{4}$, in accordance with the original study, pregnant women had difficulty in classifying the limiting factors in the task. The most frequently mentioned items that contribute to the difficulty in performing the task in second-trimester pregnant women were "sitting," "uncomfortable position," "excessive time in the same position" and "frequent 
Table 2. Test-retest reliability of question 4 of the Task Description Questionnaire.

\begin{tabular}{lcl}
\hline \multicolumn{1}{c}{ Item - Task } & $\begin{array}{c}\mathbf{k}(\boldsymbol{p}) \\
\text { 2nd gestational } \\
\text { trimester }\end{array}$ & $\begin{array}{c}\mathbf{K}(\boldsymbol{p}) \\
\text { 3rd gestational } \\
\text { trimester }\end{array}$ \\
\hline Uncomfortable position & $0.60(0.009)$ & $0.87(<0.001)$ \\
Excessive effort & $1.00(<0.001)$ & $0.61(0.004)$ \\
Excessive time in same position & $1.00(<0.001)$ & $1.00(<0.001)$ \\
Sitting & $1.00(<0.001)$ & $1.00(<0.001)$ \\
Frequent repetitions & $0.88(<0.001)$ & $0.88(<0.001)$ \\
Vibrations & $1.00(<0.001)$ & $1.00(<0.001)$ \\
Stress & $0.65(0.005)$ & $0.88(<0.001)$ \\
Fear of getting hurt & $0.77(0.001)$ & $0.73(0.001)$ \\
\hline
\end{tabular}

Note: $p<0.05$ is statistically significant, $\mathrm{k}$ : Kappa coefficients of items for gestational trimesters.

Table 1. Test-retest reliability of question 3 on the Task Description Questionnaire.

\begin{tabular}{|c|c|c|}
\hline Item - Task & $\begin{array}{c}\kappa(p) \\
\text { 2nd gestational } \\
\text { trimester }\end{array}$ & $\begin{array}{c}\kappa(p) \\
\text { 3rd gestational } \\
\text { trimester }\end{array}$ \\
\hline Handle objects above your head & $0.82(<0.001)$ & $0.62(0.003)$ \\
\hline Handle objects at belly level & $1.00(<0.001)$ & $0.77(0.001)$ \\
\hline Tilt forward trunk & $1.00(<0.001)$ & $0.78(<0.001)$ \\
\hline Tilt and rotate trunk & $1.00(<0.001)$ & $0.79(<0.001)$ \\
\hline Lift objects less than $5 \mathrm{~kg}$ & $1.00(<0.001)$ & $1.00(<0.001)$ \\
\hline Lift objects over $5 \mathrm{~kg}$ & $0.85(<0.001)$ & $0.82(<0.001)$ \\
\hline Load objects less than $5 \mathrm{~kg}$ & $1.00(<0.001)$ & $1.00(<0.001)$ \\
\hline Load objects over $5 \mathrm{~kg}$ & $0.82(<0.001)$ & $0.61(0.004)$ \\
\hline Push objects & $0.88(<0.001)$ & $0.51(0.02)$ \\
\hline Pull objects & $0.88(<0.001)$ & $0.68(0.003)$ \\
\hline Stand for long periods of time & $0.88(<0.001)$ & $0.68(0.002)$ \\
\hline Walk for long distances & $1.00(<0.001)$ & $0.87(<0.001)$ \\
\hline Climb stairs & $0.85(<0.001)$ & $0.77(0.001)$ \\
\hline Sit in an uncomfortable chair & $0.77(0.001)$ & $0.89(<0.001)$ \\
\hline Sit for long periods of time & $0.72(0.001)$ & $1.00(<0.001)$ \\
\hline Perform the same task often & $0.76(0.001)$ & $0.77(0.001)$ \\
\hline Do things in a hurry & $0.88(<0.001)$ & $0.73(0.001)$ \\
\hline Have an intense rhythm of work & $1.00(<0.001)$ & $0.88(<0.001)$ \\
\hline Be in an uncomfortable position & $0.88(<0.001)$ & $0.65(0.004)$ \\
\hline $\begin{array}{l}\text { Work with vibrations, machines, } \\
\text { instruments or vehicles. }\end{array}$ & $1.00(<0.001)$ & $0.77(0.001)$ \\
\hline Work with heat and/or humidity & $1.00(<0.001)$ & $0.82(<0.001)$ \\
\hline Stress & $0.66(0.004)$ & $0.75(0.001)$ \\
\hline
\end{tabular}

Note: $p<0.05$ is statistically significant, $\mathrm{k}$ : Kappa coefficients of items for gestational trimesters.

repetitions." For the third gestational trimester, the most frequently reported tasks were the same as those mentioned above, and the second most frequently reported item, in contrast to second-trimester pregnant women, was the "stress" factor, which made the labor task harder. For $\mathrm{Q}_{5}$, the Spearman correlation between test and retest was excellent for the efforts required in the second gestational trimester $(\rho=0.96 ; p<0.001)$ and in the third gestational trimester $(\rho=0.78 ; p=0.001)$. The coefficient of determination $\rho^{2}$ suggests that more than half of the participants showed behaviors associated with $Q_{5}$ in the second $\left(\rho^{2}=0.92\right)$ and third $\left(\rho^{2}=0.61\right)$ quarters. For $\mathrm{Q}_{6}$, the Spearman correlation indicated excellent correlation between test and retest during the second gestational trimester $(\rho=0.79 ; p=<0.001)$ and moderate correlation for the same comparison during the third trimester $(\rho=0.52 ; p=0.02)$. For test-retest comparison, the major musculoskeletal complaints were located in the abdomen and thoracolumbar spine, regardless of the gestational period. The coefficient of determination $\rho^{2}$ suggests that more than half of the sample showed test-retest agreement in Q6 in the second trimester $\left(\rho^{2}=0.62\right)$ and fewer women showed this agreement in the third trimester $\left(\rho^{2}=0.27\right)$.

\section{DISCUSSION}

Reproducibility analysis of the TDQ questionnaire indicated good agreement and moderate to excellent agreement for labor working conditions reported by pregnant women in the second and third trimesters of gestation. The TDQ questionnaire is a useful tool for identifying labor tasks and enables verification of which is harder to execute as well as understanding the aforementioned body discomfort of pregnant workers. Reproducibility between quarters was higher than in the original study ${ }^{(16)}$. We found great variation in the test-retest reproducibility coefficients of the TDQ. In Cheng et al. ${ }^{(16)}$, question 3 had poor agreement for "lifting objects over $5 \mathrm{~kg}$," "pulling object," "standing for long periods of time," "climbing stairs," "having an intense rhythm of work" and "being in an uncomfortable position" for women in the second trimester, while "pushing objects," "being in an uncomfortable position" and "working with machine vibrations or vehicles" had poor agreement for the third trimester. Our participants presented more cohesive responses than the original study, which may suggest the importance of inclusion and exclusion factors of the sample for the reproducibility of the application of the TDQ.

To achieve high reproducibility, a pilot study was necessary for researchers to become proficient at applying the TDQ, improving how questions were asked and how the TDQ was applied. Our sample size was large enough to detect such behaviors and there was no sample loss between the application of the test and retest, given the process of convincing patients to take part in the research. Only the "stress" item of question 3 presented a moderate correlation when evaluated in the second trimester. For the third gestational trimester, "handling objects above the head," "carrying objects weighing more than 5 kg," "pushing and 
pulling objects" and "uncomfortable standing" had a moderate correlation. Body modifications can prevent pregnant women from carrying out some activities, such as those that require speed, concentration, precision, transporting of loads, long hours of work and remaining seated for a long time, since they represent discomfort and sometimes even a great threat to health ${ }^{(24-26)}$.

The identification of barriers to working in the second and third quarter indicated maximum and good reliability, respectively. Halpern et al. ${ }^{(19)}$ tested the reliability of a questionnaire about occupational risk factors for low back pain in 106 workers, with very similar items to question 4, and showed a $\mathrm{k}$ between maximum and poor. The main limiting factors to accomplishing the task were related to remaining in the same position for a long time and the discomfort generated by this, and other activities that imply repetition and stress. Some studies ${ }^{(8,27)}$ suggest that physical demands and work-induced stress during pregnancy may induce preterm birth, low birth weight, premature rupture of the membranes and health problems for pregnant women. The effort required by women in the second and third gestational trimesters presented an excellent correlation. This was observed in the majority of participants. In the third trimester, the workload reduces due to pregnancy-related symptoms or more medical consultations/examinations. In addition, pregnant women may reduce their career aspirations, changing their focus from work to the newborn. Such reasons might affect correlations during the two trimesters, thereby not increasing along with gestation development ${ }^{(10,27,28)}$.

Employed pregnant women presented an excellent correlation in describing their discomfort in performing labor tasks during the second trimester and presented a moderate correlation in doing so in the third trimester. The original study reported high correlations for discomfort only in the third trimester ${ }^{(16)}$. Fewer women reporting pain may indicate that in the third trimester they may find it more difficult to locate pain points over the body, or that body changes induced by fetal growth induce variability in pain sensitivity and location. The abdomen and thoracolumbar spine were the anatomical structures with the major musculoskeletal complaints in the second and third gestational trimesters. In Carvalho et al. ${ }^{(17)}$, $68 \%$ of pregnant women reported low back pain, among whom $43.9 \%$ reported that low back pain started in the second trimester. In addition, $6 \%$ of them reported that the pain radiated to the region of the abdomen. The etiology of low back pain in pregnancy is not well defined, but it is known to be multifactorial; however, the increase in total gestational body mass leads to instability of the sacroiliac joint, increased flexibility of the spine due to the action of relaxing and increasing lumbar pain, thereby compromising quality of life and reducing work performance. All these facts generate financial losses due to routine dismissals from their work activities ${ }^{(29,30)}$.

\section{CONCLUSIONS}

This study showed that the reproducibility of the TDQ encourages its application among employed pregnant women. Agreement over the TDQ ranged from good to total, reflecting the good understanding of the tool. Therefore, it was proven that it is a simple, easy and fast-application instrument. No reproducibility studies of this type of questionnaire have previously been applied in Brazil. In summary, the health of pregnant woman can be investigated by using the TDQ, where the detection of imbalances in the occupational environment should be reversed, both by employers and women.

\section{AVAILABILITY OF DATA AND MATERIALS}

Please contact author for data requests.

\section{AUTHOR'S CONTRIBUTION}

PCR and FFS designed the research. PCR, GMM and LM performed statistical analysis. PCR and GMM interpreted the data and wrote the manuscript. PCR, GMM, FFS and LM critically revised the manuscript. All the authors read and approved the final manuscript.

\section{CONFLICTS OF INTEREST}

The authors declare that they have no competing interests.

\section{AUTHOR DETAILS}

2. Universidade de São Paulo (USP), São Paulo (SP), Brazil.

\section{REFERENCES}

(1) Cheng PL, Dumas GA, Smith JT, Leger AB, Plamondon A, McGrath MJ, Tranmer JE. Analysis of self-reported problematic tasks for pregnant women. Ergonomics. 2006a;49(3):282-292.

(2) Da Rosa PC, Sperandio FF, Sacomori C, Cardoso F. Análisis de las actividades ocupacionales en gestantes con dolor lumbar de Brasil. Revista Internacional de Medicina y Ciencias de la Actividad Física y del Deporte. 2012;48:3-3

(3) Birks L, Casas M, Garcia AM, Alexander J, Barros H, Bergström A, et al. Occupational exposure to endocrine-disrupting chemicals and birth weight and length of gestation: a European meta-analysis. Environ Health Perspect. 2016;11:1785.

(4) Guendelman S, Gemmill A, MacDonald LA. Biomechanical and organisational stressors and associations with employment withdrawal among pregnant workers: evidence and implications. Ergonomics. 2016:59(12):1-12.

(5) Bonzini M, Palmer KT, Coggon D, Carugno M, Cromi A, Ferrario MM. Shift work and pregnancy outcomes: a systematic review with meta-analysis of currently available epidemiological studies. BJOG. 2011;118(12):14291437.

(6) Goodman JM, Guendelman S, Kjerulff KH. Antenatal Maternity Leave and Childbirth Using the First Baby Study: A Propensity Score Analysis. Womens Health Issues. 2017;27(1):50-59.

(7) Kim E, Park H, Hong Y, Ha M, Kim Y, Lee B, Ha EH. Effect of maternal job strain during pregnancy on infant neurodevelopment by gender at 6 and 12 months: Mothers and Children's Environmental Health (MOCEH) study. AOEM. 2015;27(8):1-10.

(8) Van Beukering MDM, Van Melick MJGL, Mol BW, Frings-Desen MHW, Hulshof CTJ. Physically demanding work and preterm delivery: a systematic review and meta-analysis. Int Arch Occup Environ Health. 2014;87(8):809-834. 
(9) Vigoureux S, Blondel B, Ringa V, Saurel-Cubizolles MJ. Who are the Women Who Work in Their Last Month of Pregnancy? Social and Occupational Characteristics and Birth Outcomes of Women Working Until the Last Month of Pregnancy in France. Matern Child Health J. 2016;20(9):1774-1779.

(10) Henrotin J, Vaissière M, Etaix M, Dziurla M, Malara S, Lafon D. Exposure to occupational hazards for pregnancy and sick leave in pregnant workers: a cross-sectional study. AOEM. 2017;29(12):1-11.

(11) Neupane S, Nwaru BI, Wu Z, Hemminki E. Changes in work behavior during pregnancy in rural Anhui, China from 2001-03 to 2009: a population based cross-sectional study. BMC Womens Health. 2016;16(1):34.

(12) Kim H, Kwon H, Rhie J, Lim S, Kang Y, Eom S, et al. The relationship between spontaneous abortion and female workers in the semiconductor industry. AOEM. 2017;29(49):1-12.

(13) Yeh SS, Lee CN, Wu YH, Tu NC, Guo YL, Chen PC, Chen CH. Occupational Hazard Exposures and Depressive Symptoms of Pregnant Workers. J Occup Environ Med. 2017.

(14) Coluci MZO, Alexandre NMC, Milani D. Construção de instrumentos de medida na área da saúde. Cien Saude Colet. 2015;20(3):925-936.

(15) Sperandio FF, Gontijo LA, Krawulski E. Investigando a tarefa e os fatores de risco em gestantes trabalhadoras: tradução e adaptação transcultural do" Task Description Questionnaire" no Brasil. Revista Digital-Buenos Aires. 2007;112.

(16) Cheng PL, Dumas GA, Smith JT, Leger AB, Plamondon A, McGrath MJ, Tranmer JE. Reproducibility of task description questionnaire for working pregnant women. Work. 2006b;24:1-9.

(17) Carvalho F, Melo RB. Stability and reproducibility of semi-quantitative risk assessment methods within the occupational health and safety scope. Work. 2015;51(3):591-600.

(18) Peersen K, Munkhaugen J, Gullestad L, Dammen T, Moum T, Otterstad JE. Reproducibility of an extensive self-report questionnaire used in secondary coronary prevention. Scand J Public Health. 2017;45(3):269-276.
(19) Halpern M, Hiebert R, Nordin M, Goldsheyder D, Crane M. The test-retest reliability of a new occupational risk factor questionnaire for outcome studies of low back pain. Appl Ergonom. 2001;32(1):39-46.

(20) Landis JR, Koch GG. The measurement of observer agreement for categorical data. Biometrics. 1977a;33(1):159-174.

(21) Landis JR, Koch GG. The measurement of observer agreement for categorical model. Biometrics. 1977b;33:671-679.

(22) Portney LG, Watkins MP. Foundations of clinical research: applications to practice. $3^{\text {rd }}$ Ed. FA Davis; 2015.

(23) Sim J, Wright CC. The Kappa Statistic in Reliability Studies: Use, Interpretation, and Sample Size Requirements. Phys Ther. 2005;85(3):257268.

(24) Salihu HM, Myers J, August EM. Pregnancy in the workplace. Occup Med. 2012;62(2):88-97; doi: 10.1093/occmed/kqr198.

(25) Campos R, Mazon LM, Melnek JS, Melo JS, Kraschinski GCW, Melo $\mathrm{GPH}$, et al. O resgate do direito das trabalhadoras gestantes: o trabalho interdisciplinar do pet saúde no sistema único de saúde. REID. 2016;16:7590.

(26) Palmer KT, Bonzini M, Harris EC, Linaker C, Bonde JP. Work activities and risk of prematurity, low birthweight and preeclampsia: an updated review with meta-analysis. Occup Environ Med. 2013;70(4):213-222.

(27) Katz VL. Work and work-related stress in pregnancy. Clin Obstet Gynecol. 2012;55(3):765-773.

(28) Baima CTS, Barroso FAL, Lucena J, Almeida CSC, Dos Santos APSA. Afastamento do trabalho por pacientes gestantes: principais causas de absentismo. Rev Bras Med Trab. 2016;14(1):13-8.

(29) Sencan S, Ozcan-Eksi EE, Cuce I, Guzel S, Erdem B. Pregnancy-related low back pain in women in turkey: prevalence and risk factors. Ann Phys Rehab Med. 2018;61(1):33-37.

(30) Morino S, Ishihara M, Umezaki F, Hatanaka H, lijima H, Yamashita M, et al. Low back pain and causative movements in pregnancy: a prospective cohort study. BMC Musculoskeletal Disorders. 2017;18(416). 